\title{
Experimental Study of Noise Shielding by a NACA 0012 Airfoil
}

\author{
Florence V. Hutcheson ${ }^{1}$, Christopher J. Bahr ${ }^{2}$, Russell H. Thomas ${ }^{1}$ \\ Aeroacoustics Branch, NASA Langley Research Center, Hampton VA. 23681, USA \\ and \\ Daniel J. Stead ${ }^{3}$ \\ Science and Technology Corporation, Hampton VA. 23681, USA
}

\begin{abstract}
The effects of sound source location, Mach number and angle of attack on the shielding of a laser-induced sound source by a NACA 0012 airfoil are examined. The sound source is a small plasma generated by a high energy, laser beam focused to a point. In-flow microphone measurements are acquired in the midspan plane of the airfoil over a broad range of streamwise stations, and shielding levels are calculated over different frequency ranges from the measurements acquired with and without the airfoil installed. Shielding levels are shown to increase as the source is positioned closer to the mid-chord of the airfoil, and to significantly decrease with increasing flow Mach number, except when the source is positioned near the leading edge of the airfoil. Both with and without flow, changes in angle of attack are associated with a corresponding shift of the shadow region. Finally, the effects of multipath signals, observer distance and signal scatter on the measured shielding levels are discussed.
\end{abstract}

\section{Introduction}

As air traffic continues to increase, the reduction of aircraft noise is an objective that remains at the forefront for the aircraft industry. In addition to developing quieter engines and airframe systems, an approach that is considered in the design of quieter aircraft is the shielding of noise components. For example, engines can be placed above an aircraft wing or fuselage to partially shield engine noise radiation, or the lower side of the inlet of an engine can be extended forward (scarf inlet ${ }^{1}$ ) to reflect inlet noise away from the ground. This approach to noise reduction has been the subject of growing interest ${ }^{2-7}$ which has revealed a need for further validation and improvement of current noise scattering prediction tools. To address this need, a NATO task group led by NASA and DLR representatives set out to establish an experimental database for the validation of computational methodologies. This effort included the execution of dedicated noise scattering tests using a common airfoil as the scattering surface and a well-defined, laser-induced, impulsive sound source. In these experiments, the effects of flow and source location on shielding were evaluated. One of these dedicated noise scattering tests was conducted at NASA Langley Research Center and is the subject of this paper. Corresponding experiments were conducted by DLR ${ }^{\mathbf{8}}$ and ONERA. The test setup, data acquisition procedures and noise source characteristics are presented in the first part of this paper, followed by an examination of the effects of flow, source and observer locations and airfoil angle of attack on shielding. The paper concludes with a summary of the test results.

\footnotetext{
${ }^{1}$ Senior Research Engineer, AIAA Associate Fellow

${ }^{2}$ Research Engineer, AIAA Senior Member

${ }^{3}$ Test Engineer
} 


\section{Experimental Setup}

This experiment was conducted in NASA Langley's Quiet Flow Facility (QFF). The QFF is an anechoic facility equipped with a 0.61 by $0.91 \mathrm{~m}$ rectangular open jet nozzle. Side plates attached to the $0.61 \mathrm{~m}$ sides of the nozzle are used to support models above the nozzle, while the $0.91 \mathrm{~m}$ sides of the test section remain open. The test model used in the present experiment as the noise scattering (or shielding) surface is a two-dimensional NACA 0012 airfoil with a $0.245 \mathrm{~mm}(0.010$ ") thick trailing edge, a $0.91 \mathrm{~m}$ span, and a $0.20 \mathrm{~m}$ chord. The airfoil was positioned at the center of the test section and each end of the airfoil was mounted to a rotating plate to allow for angle of attack changes. A $1 / 8$ " 4138 B\&K microphone equipped with a B\&K UA 0355 nose cone and mounted on a linear traverse was used to acquire the acoustic measurements inside the test section at different streamwise stations. A picture of the test setup is shown in Figure 1.

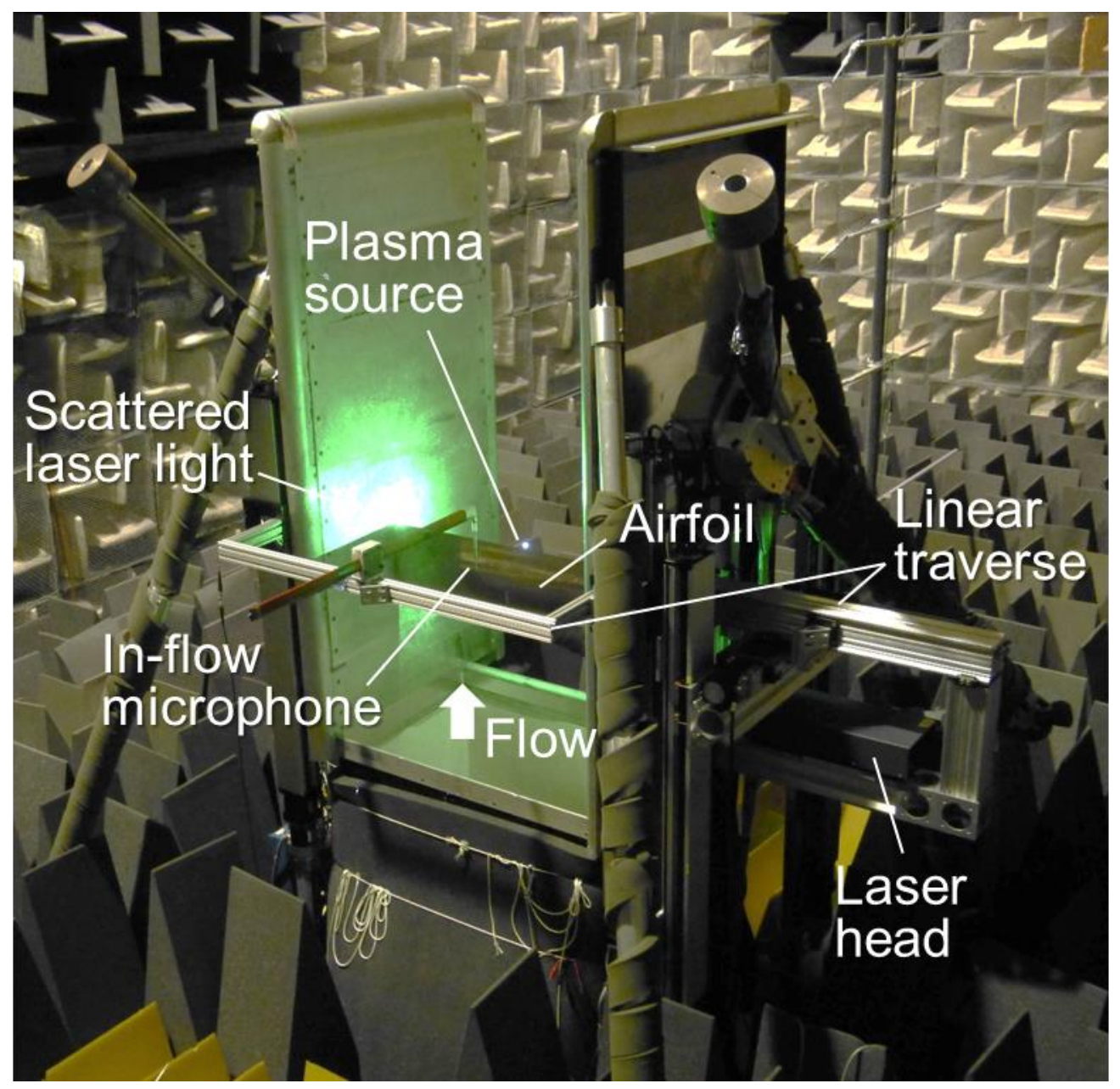

Figure 1. QFF experimental set up.

The sound source was a laser-induced plasma which, once formed, rapidly expands to generate a nearly omnidirectional pressure wave that propagates as an isentropic acoustic wave in the far field. ${ }^{9}$ The localized plasma was generated by a high energy, focused laser beam. The laser system used was a Nd:YAG, Gemini PIV laser, with an energy pulse of $120 \mathrm{~mJ}$, a wavelength of $532 \mathrm{~nm}$ and a pulse width of 3 to $5 \mathrm{~ns}$. As depicted in Fig. 2, the laser system was positioned behind one of the test section walls (which was modified to incorporate a $0.95 \mathrm{~cm}$ thick tempered 
glass window). A set of $7.62 \mathrm{~cm}$ diameter achromatic, expansion, collimating and focusing lenses was used to focus the laser beam at the test section midspan.

To minimize laser reflections, the path of the laser beam from the laser head to the test section wall window was enclosed by installing tubes between optical lenses, and between the focusing lens and the test section wall window (see Fig. 3). A photodetector was also positioned near the laser window to record the plasma (sound source) occurrence time.

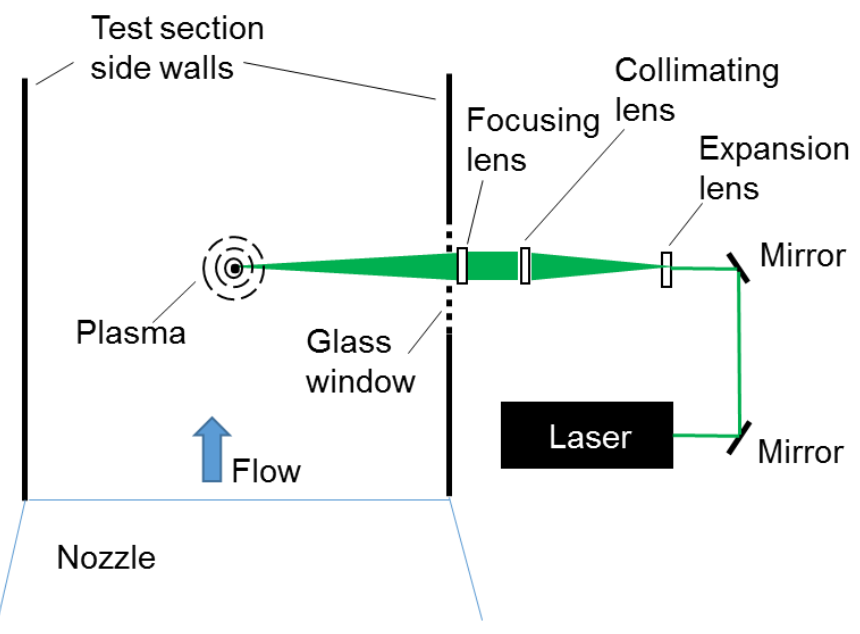

Figure 2. Sketch of laser and optical lens set-up.
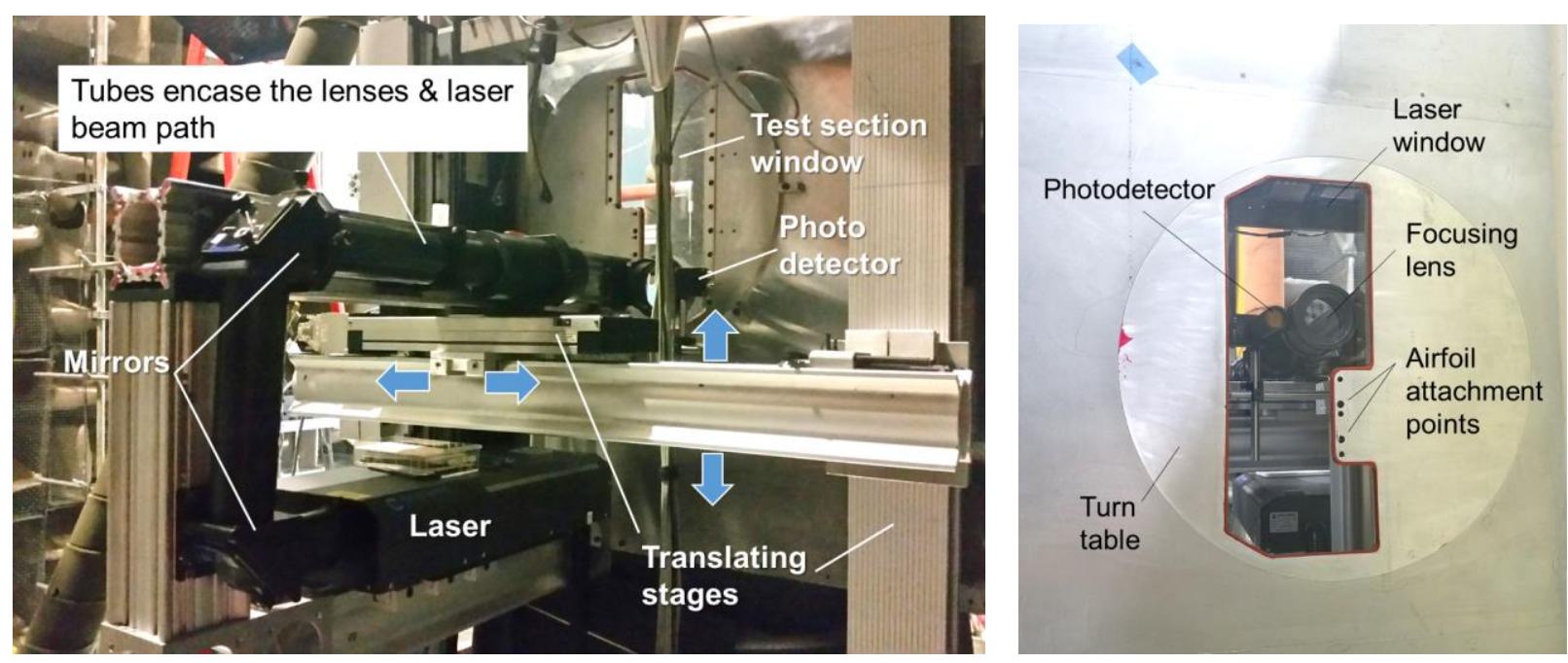

a)

b)

Figure 3. Laser and optical lens assembly; a) view from behind the test section wall; b) view from inside the test section.

The traverse system used to position the in-flow microphone and the laser/optic assembly (shown in Figs. 1 and 3a) was designed to be compact and rigid in order to minimize flow-induced vibrations. It was used to traverse the inflow survey microphone in the streamwise direction, and the laser system assembly in both streamwise and crosswise directions to position the sound source at chosen locations. The motors of the traverse system were turned off during the acquisition of each data point to avoid possible noise contamination. 


\section{Data Acquisition and Processing}

Each set of in-flow (survey) microphone measurements was acquired with and without the airfoil installed (i.e., for shielded and unshielded conditions). These measurements were acquired in the midspan plane of the airfoil, one chord away $(200 \mathrm{~mm})$ from the test section centerline (which is also the airfoil chordline when at $0^{\circ}$ angle of attack). They were also acquired two chords away $(400 \mathrm{~mm})$ for a subset of test cases. Microphone measurements performed two chords away from the test section centerline placed the microphone outside of the test section, and were therefore only performed without flow. The sound source (plasma) and microphone survey locations are depicted in Fig. 4. The survey microphone was traversed in the streamwise direction, up to $200 \mathrm{~mm}$ upstream and $400 \mathrm{~mm}$ downstream of the airfoil leading edge. In Fig. 4, the open black circles indicate microphone locations where measurements were acquired for most test configurations, while the smaller closed circles indicate measurement locations used for only a subset of test cases. The sound source was positioned, respectively, at $0 \%$ (airfoil leading edge), 25\%, 50\%, 60\%, $75 \%$ and $100 \%$ chord (corresponding to streamwise stations, $\mathrm{x}=0,50,100,140,150$ and $200 \mathrm{~mm}$ when the airfoil is at $0^{\circ}$ angle of attack). For the $0^{\circ}$ angle of attack configuration, additional measurements were acquired with the source positioned upstream of the airfoil at $\mathrm{x}=-50 \mathrm{~mm}$, and downstream at $\mathrm{x}=320 \mathrm{~mm}$. For each of these locations, the source was positioned at a constant normal distance of $25 \mathrm{~mm}$ from the airfoil surface (or from the extended chordline when upstream or downstream of the airfoil). When the source was positioned at $70 \%$ chord, additional measurements were acquired with the source at a normal distance of $40 \mathrm{~mm}$ from the airfoil surface. The microphone surveys were performed for three flow speeds (Mach numbers $0,0.087$ and 0.16 ) and three geometric angles of attack (AOA), $0^{\circ}$ and $+/-13.1^{\circ}$, corresponding to effective aerodynamic angles of attack, $\alpha^{*}$, of $0^{\circ}$ and $+/-6^{\circ}$, respectively. When positioned at a non-zero angle of attack, the airfoil was tripped by placing a $0.4 \mathrm{~mm}$ thick and $6 \mathrm{~mm}$ wide strip of aluminum tape at $60 \%$ chord on the airfoil pressure side. While the microphone survey locations remained unchanged with changes in airfoil angle of attack, the chordwise location of the sound source and constant distance of $25 \mathrm{~mm}$ (or $40 \mathrm{~mm}$ at $70 \%$ chord) between the sound source and the airfoil surface were maintained.

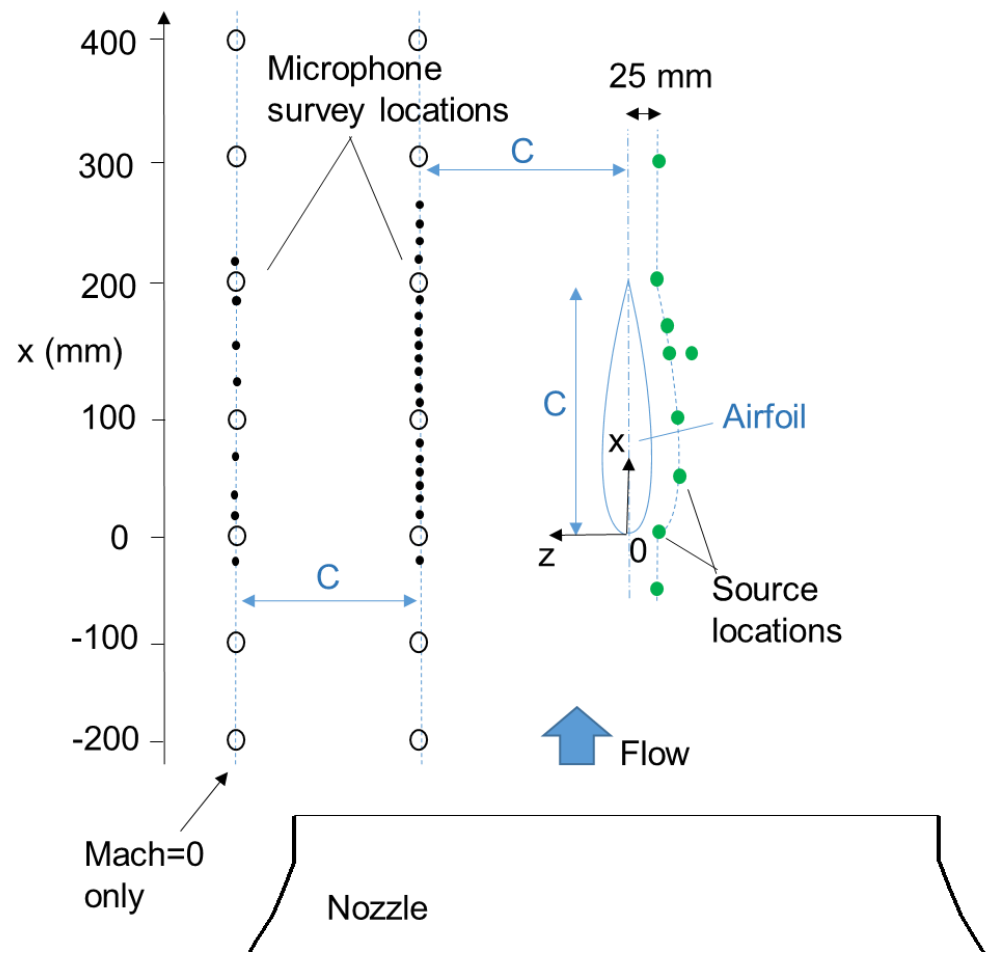

Figure 4. Microphone survey and noise source locations; $C=20 \mathrm{~mm}$. 
The laser-induced sound source was generated with a repetition rate of $5 \mathrm{~Hz}$, and the survey microphone response was recorded for $20 \mathrm{~s}$, creating time records of 100 acoustic pulses per data point. The survey microphone data were acquired simultaneously with two different sampling rates, $250 \mathrm{kHz}$ (as in the corresponding DLR and ONERA tests) and $10 \mathrm{MHz}$. The acoustic datasets acquired at $10 \mathrm{MHz}$ are used for the results presented in this paper. The low-pass and high-pass filters were set at $100 \mathrm{kHz}$ and $150 \mathrm{~Hz}$, respectively. For the processing of each data point acquired, the time signal is gated with a $25 \%$ Tukey window to isolate the portion of the signal that corresponds to the sound that is directly propagating from the source or to the scattered sound that is propagating from the leading and trailing edges of the airfoil. This gating effectively rejects reflections from facility surfaces and only retains the portions of the time signal that contain the acoustic pulses of interest. The gated time signals are then superposed and ensembleaveraged. The laser Q-switch (trigger) and photodetector signals (which were also recorded) are used in this process to properly identify the acoustic pulses and superpose the gated signals. Finally, the spectra are calculated using data blocks that are zero-padded to the number of samples needed to obtain a frequency resolution of $61 \mathrm{~Hz}$, to match the processing parameters used by DLR and ONERA. Two types of spectra are calculated. The first one is calculated from the ensemble-averaged gated time signals, while the second one is obtained through averaging of the power spectra obtained from each individual gated time signal. In this paper, these spectra will be referred to as averagedsignal spectra and root-mean-squared (rms) spectra, respectively. In the absence of transient events (such as a gust hitting the in-flow microphone) or scattering of the time signal due to turbulence, the averaged-signal and rms spectra were found to be nearly identical. Thus, unless indicated otherwise, the results presented in Section 5 are calculated from averaged-signal spectra.

Examination of the in-flow microphone time signals acquired with the wind tunnel flow turned on revealed the presence of low frequency noise contamination (likely produced from flow-induced vibrations which, although minimized, could not be completely eliminated). This noise contamination was removed by applying a phaseless ${ }^{10} 2$ $\mathrm{kHz}$ high-pass digital filter to the data. An example of a contaminated microphone signal is displayed in Fig. 5. For this test case, the flow Mach number is 0.16 ; the airfoil angle of attack is $0^{\circ}$; the sound source is aligned with the airfoil trailing edge; and the microphone is positioned $100 \mathrm{~mm}$ downstream of the airfoil leading edge (and one chord away from the airfoil). This sample signal also shows the occurrence of what appears to be flow-induced "ringing" which shows up as a small bump in the spectra near $30 \mathrm{kHz}$ (as seen in Fig. 6). This "ringing" was only observed in time signals recorded from microphones equipped with a nose cone and immersed in the test section flow, and showed a dependence on the angle of incidence from the source to the microphone. Although this phenomenon appears to be associated with the geometry of the nose cone (as the wavelength of the "ringing" relates to some of the cone's dimensions), its cause remains under investigation.

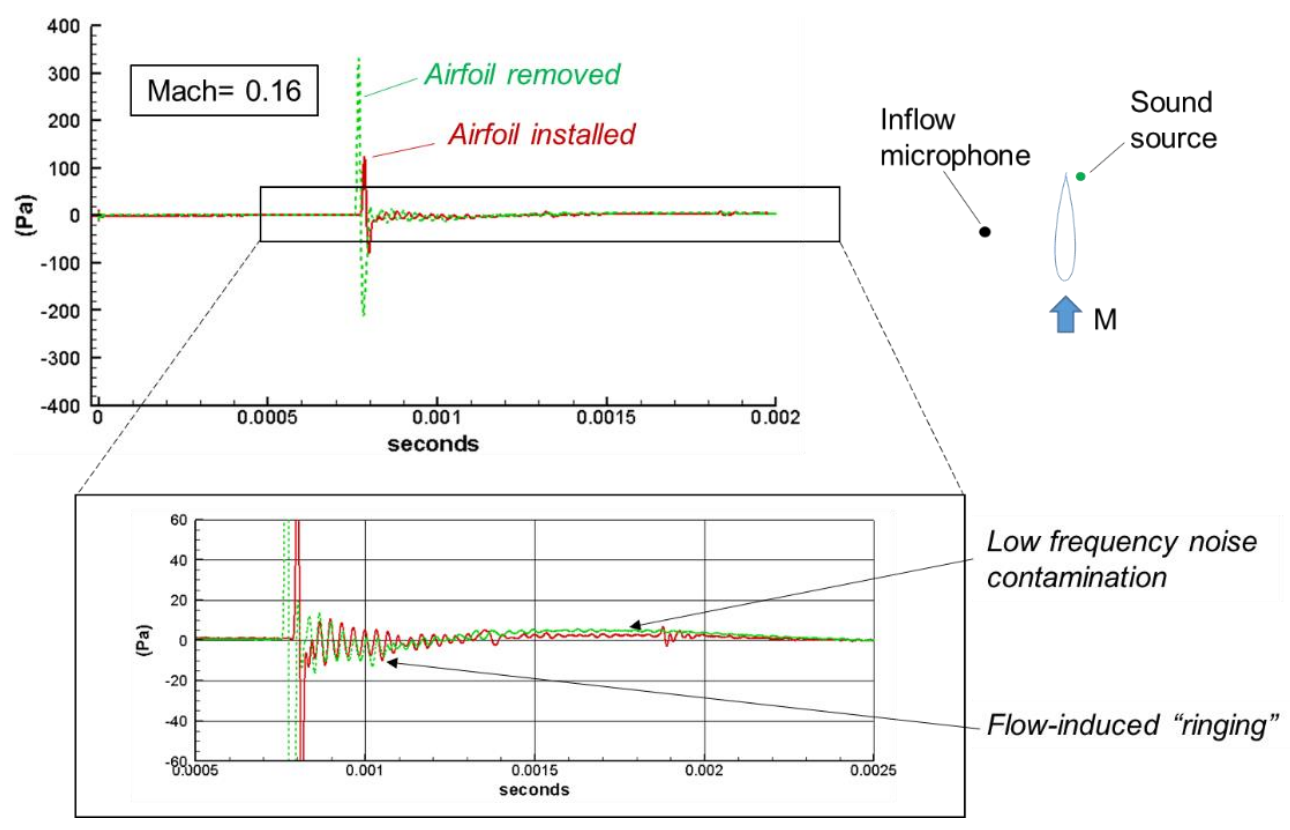

Figure 5. Flow-induced noise contamination. 
The impact of the low frequency noise contamination on the spectra and shielding levels obtained with and without the application of the $2 \mathrm{kHz}$ high-pass digital filter is shown in Fig. 6 for the same test case as in Fig. 5.
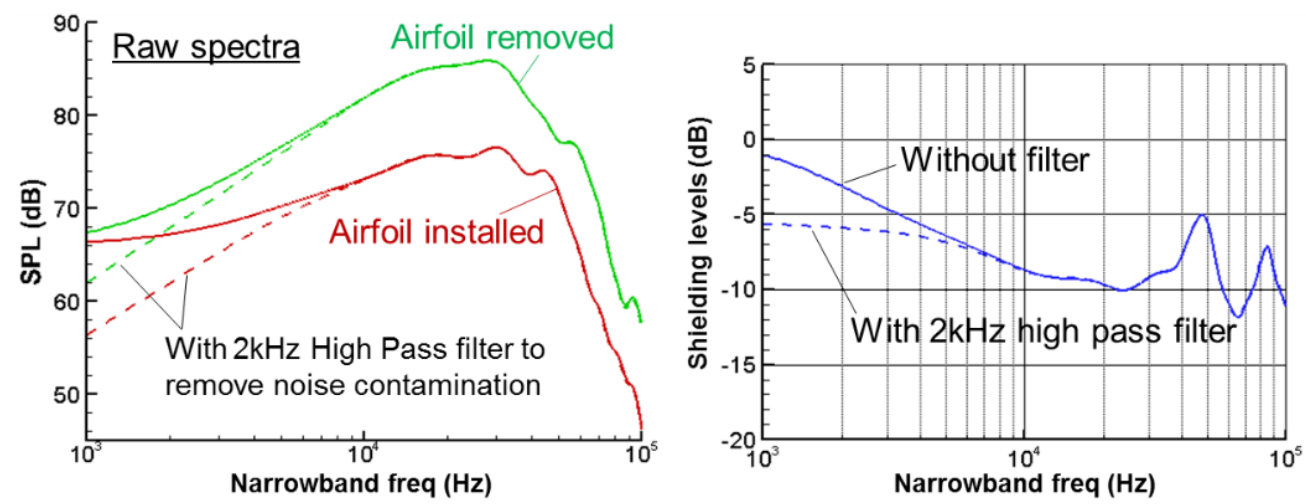

Figure 6. Effect of low frequency noise contamination on spectra and shielding levels (flow Mach number of 0.16).

The last step in the processing of the acquired test data is the calculation of the frequency-integrated shielding levels, $\gamma_{p}^{n}\left(f_{c}\right)$ and $\gamma_{p}^{n}(\infty)$, where

$$
\gamma_{p}^{n}\left(f_{c}\right)=20 \log _{10}\left(\eta^{n}\left(f_{c}\right)\right)
$$

is the octave band normalized shielding level which is calculated over octave bands of center frequencies, $\mathrm{f}_{\mathrm{c}}=7,14$, 28 and $56 \mathrm{kHz}$, respectively, and

$$
\gamma_{p}^{n}(\infty)=20 \log _{10}\left(\eta^{n}(\infty)\right)
$$

is the overall normalized shielding level. In Eqs. (1) and (2), $\eta^{n}\left(f_{c}\right)$ and $\eta^{n}(\infty)$ are, respectively, the octave band and overall shielding factors which are defined as

$$
\eta^{n}\left(f_{c}\right)=\left[\frac{\sqrt{2}}{f_{c}} \int_{f_{c} / \sqrt{2}}^{f_{c} \sqrt{2}} \eta^{2}(f) d f\right]^{1 / 2}
$$

and

$$
\eta^{n}(\infty)=\left[\frac{1}{\left(f_{u}-f_{l}\right)} \int_{f_{l}}^{f_{u}} \eta^{2}(f) d f\right]^{1 / 2}
$$

where $f_{u}=\sqrt{2} * 56 \mathrm{kHz}, f_{l}=\frac{1}{\sqrt{2}} * 7 \mathrm{kHz}$ and

$$
\eta^{2}(f)=p_{s}^{2}(f) / p_{i}^{2}(f)
$$


In Eq. (5), $p_{i}$ is the acoustic pressure from the isolated source field (i.e., airfoil removed) and $p_{s}$ is the acoustic pressure from the scattered field (i.e., airfoil installed). Note that the overall frequency range, octave bands and shielding quantities defined above were chosen to be consistent with those used in the analysis of the data acquired in the companion tests performed at DLR and ONERA.

\section{Noise Source Characteristics}

\section{A. Sound source repeatability}

The repeatability of the acoustic pulse generated by the laser-induced sound source was monitored and verified throughout the test by repeating the acquisition of a reference data point at different stages of the test. The averaged waveforms produced by the sound source for the data points acquired near the beginning, mid-portion and end of the test are shown in Fig. 7. The signal waveforms recorded by the microphone are seen to be nearly identical, demonstrating the repeatability of the sound source produced by the laser system. For these sound source repeatability checks, the airfoil is positioned at $0^{\circ}$ angle of attack; the flow Mach number is 0 ; the sound source is positioned at $\mathrm{x}$ $=320 \mathrm{~mm}$ (and $25 \mathrm{~mm}$ from the test section center line), while the microphone is positioned 1 chord away from the airfoil, at $\mathrm{x}=300 \mathrm{~mm}$.

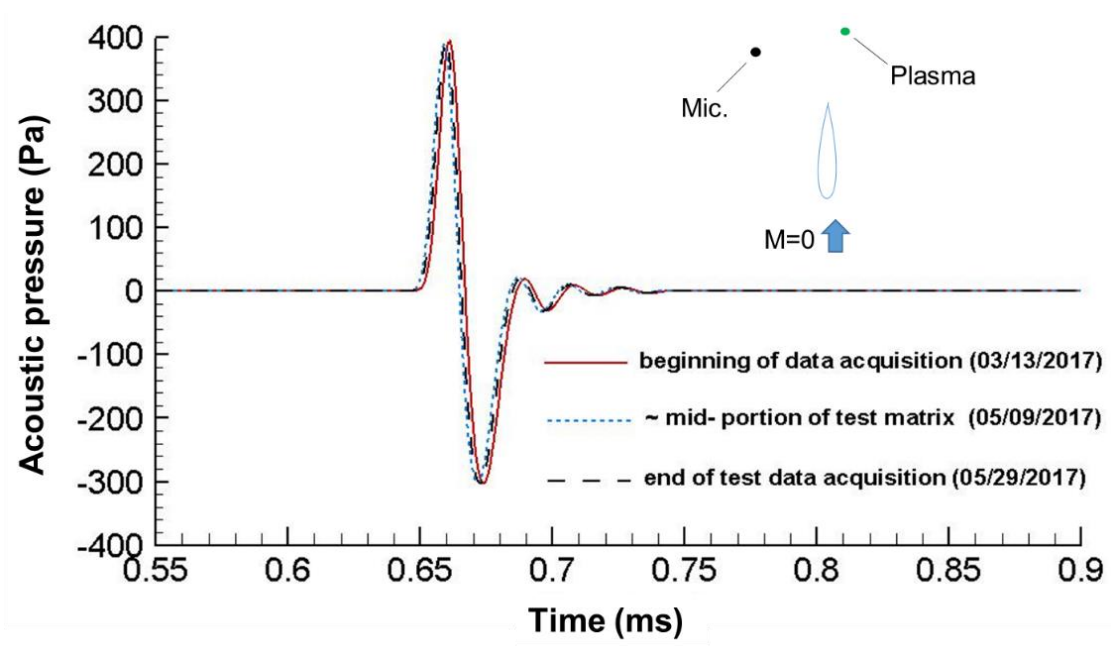

Figure 7. Laser-induced sound source waveform repeatability.

\section{B. Sound source directivity}

Acoustic measurements of the isolated sound source performed over a broad range of microphone locations at Mach 0 were used to characterize the directivity of the sound source. The raw spectra (i.e., as measured) and freefield corrected spectra (i.e., measured with no microphone grid cap and corrected with manufacturer data) obtained from these acoustic measurements are presented in Fig. 8. The sound pressure levels shown are adjusted to a distance of $0.2 \mathrm{~m}$, and atmospheric absorption corrections ${ }^{11}$ have been applied to the free-field corrected spectra. The collapse of the free-field corrected spectra seen is consistent with the expected omnidirectional ("monopole-like") character of the sound source. Note that the spectra corresponding to the upstream-most $143^{\circ}$ and $150^{\circ}$ incidence angles (shown as red curves in Fig. 8) do not collapse as well with the rest of the spectra. These 2 spectra were obtained from measurements acquired with the microphone positioned the furthest away from the sound source. Atmospheric absorption corrections at these measurement locations being larger (by up to $1 \mathrm{~dB}$ at $60 \mathrm{kHz}$ ) than at the other locations might be a source of uncertainty. Yet, all peak spectral levels collapse within $1 \mathrm{~dB}$ verifying the approximate omnidirectional character of the sound source.

The effect of free stream flow on the sound source directivity is shown in Fig. 9 for the largest flow Mach number tested, $M=0.16$. The source is positioned at the streamwise station $x=200 \mathrm{~mm}$, and the observer line is one chord away from the test section centerline. Overall sound pressure levels (OASPL) were calculated at each observer location from measurements obtained with and without flow. OASPL for different octave bands and the full 5 to 80 $\mathrm{kHz}$ frequency range are shown. It is seen that the presence of the flow leads to a decrease in sound upstream of the 
source and a sound amplification downstream. This effect on the OASPL is observed to be most significant above 20 $\mathrm{kHz}$ (i.e., for the two highest frequency bands), while little impact is apparent in the lower frequency bands. This change in the source directivity indicates that in the presence of flow, the plasma source does not behave as a fixed point monopole, because if it were, the convective amplification of the sound would be observed upstream and a decrease downstream. ${ }^{12}$ Instead, and as numerically verified in ref. 13, the plasma source convects with the flow during sound production. The duration of the sound production is estimated to be approximately $0.1 \mathrm{~ms}$ (as shown in Fig. 7, based on the duration of the acoustic pressure signal received at the microphone), though this is likely an overestimate given that the recorded pressure signal is the convolution of the true acoustic waveform with the instrumentation impulse response. A duration of $0.1 \mathrm{~ms}$ amounts to a travel distance of about $6 \mathrm{~mm}$ at $\mathrm{M}=0.16$. The convection of the source during sound emission explains the changes in the source directivity observed with flow in this experiment. Note that in Fig. 9, the data shown are as measured. Application of the microphone free-field correction to the data, assuming a fixed source (positioned either at $\mathrm{x}=200 \mathrm{~mm}$ or $6 \mathrm{~mm}$ further downstream) for the calculation of the source emission angles when $\mathrm{M}=0.16$, would slightly accentuate the difference in OASPL between the flow and no-flow cases.

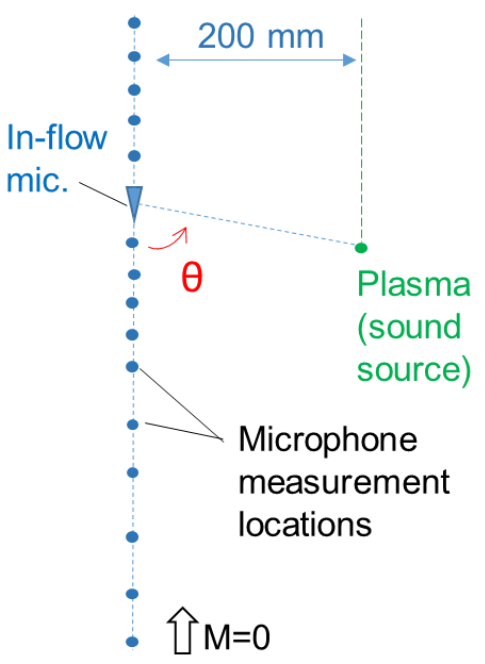

a)

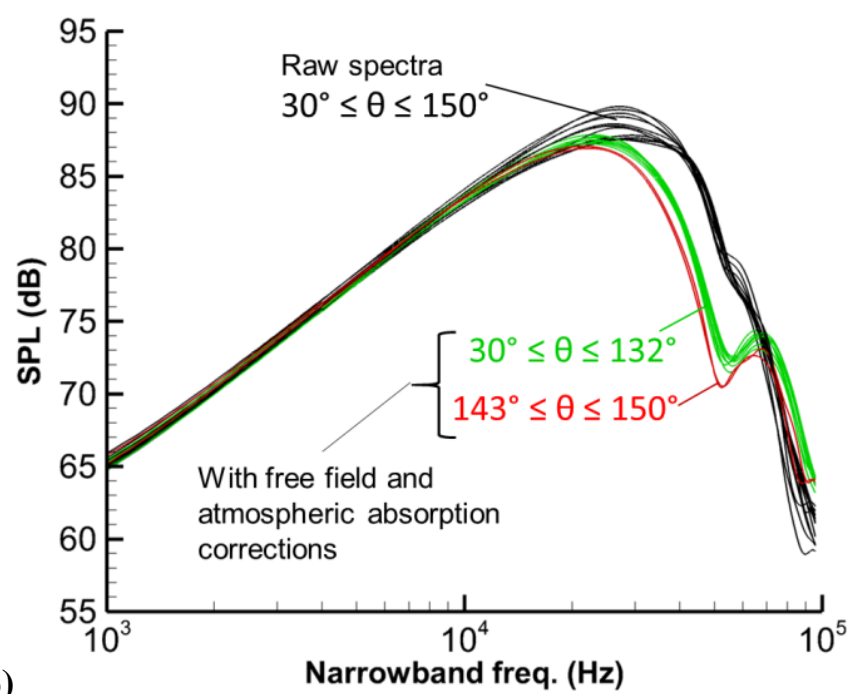

b)

Figure 8. Sound source directivity; $M=0$; a) microphone measurement locations; b) measured spectra with levels corrected to a common distance $R$ of $0.2 \mathrm{~m}$, and with and without free-field and atmospheric absorption corrections applied; the frequency binwidth is $61 \mathrm{~Hz}$. 


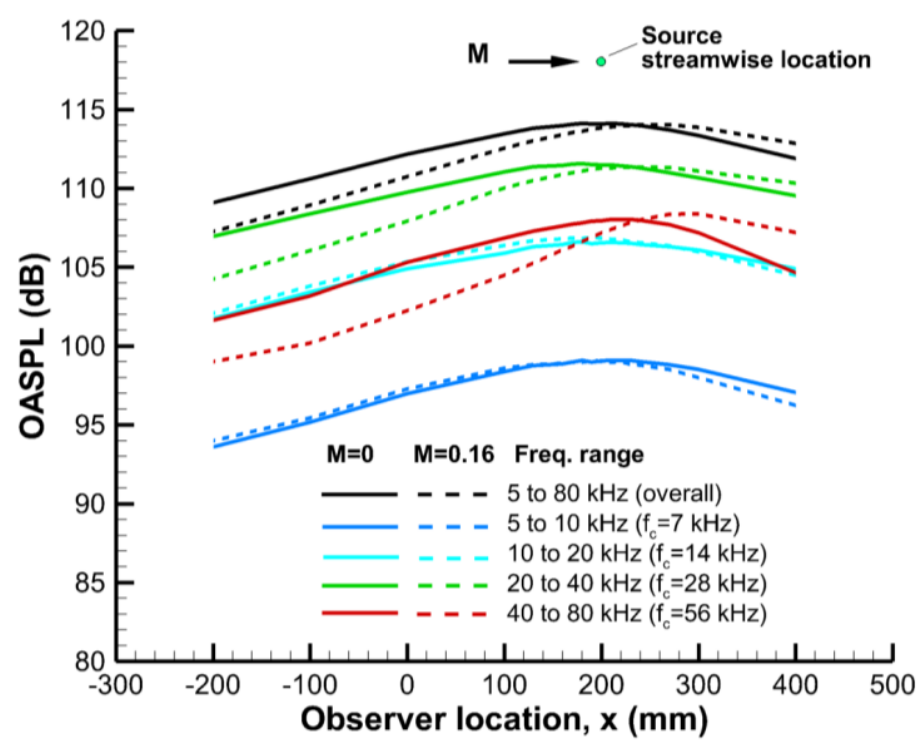

Figure 9. Effect of free stream flow on source directivity; the sound source is located at streamwise station $x=200 \mathrm{~mm}$; the observer line is located 1 chord $(20 \mathrm{~cm})$ away from the test section centerline. Data are as measured, no microphone free field nor atmospheric absorption corrections are applied.

\section{Test Results}

The results obtained for a large subset of the configurations tested are presented in this section. The effects of source location, flow, airfoil angle of attack and observer locations on shielding levels are examined. Microphone free-field corrections and atmospheric absorption corrections were not applied in the calculation of the shielding quantities presented here. Although these corrections could be clearly quantified for the isolated source test cases without flow, and closely approximated for the corresponding flow cases (by assuming a fixed source for the calculation of path lengths and emission angles), the multipath nature of the signal received at the microphone once the airfoil is installed complicated this process. Except for particular combinations of source and observer locations where the sound radiated by the source has a direct path to the observer and is not affected by the presence of the airfoil, the microphone receives sound from two different paths, the sound that is scattered at the leading edge of the airfoil and the sound that is scattered at the trailing edge. The respective portions of the time signal corresponding to the sound scattered at the leading and trailing edges of the airfoil could not always be separated. In the instances that they could, the lack of information regarding the effect of various corrections (such as microphone nose cone and atmospheric absorption corrections) on acoustic phase complicated the calculation of a corrected time signal for the separated leading edge and trailing edge signals. The error on the calculation of the shielding quantities (Eq. 1 through 5) associated with not performing these corrections is estimated to be less than $1 \mathrm{~dB}$, based on angle of incidence range and distances involved for atmospheric attenuation.

\section{A. Effect of source location}

The overall shielding levels, $\gamma_{p}^{n}(\infty)$, obtained for a subset of sound source locations tested are presented in Fig. 10. The flow Mach number is 0; the microphone measurements are performed in a line located 1 chord away from and parallel to the test section centerline; and the airfoil is at $0^{\circ}$ angle of attack. Results are shown for the source located, respectively, at $x=0,100,140,150$ and $200 \mathrm{~mm}$. When at $\mathrm{x}=140 \mathrm{~mm}$, the source is located $40 \mathrm{~mm}$ from the surface of the airfoil instead of $25 \mathrm{~mm}$ as for the other source locations. The shielding curves obtained with the source positioned at $\mathrm{x}=0$ and $200 \mathrm{~mm}$ (i.e., at the leading edge and trailing edge of the airfoil) are seen to be nearly symmetric about the airfoil mid-chord station, and both indicate a very small increase in noise (positive values of $\gamma_{p}^{n}(\infty)$ ) at the locations where the observer has a direct line of sight with the source, and receives both the sound radiated from the source as well as the sound that is scattered at the airfoil's edge. This increase in sound can be 
directly observed from the pressure signals and corresponding spectra shown in Fig. 11 for one of these observer locations (source at $\mathrm{x}=200 \mathrm{~mm}$ and microphone at $\mathrm{x}=300 \mathrm{~mm}$ ). In Fig. 11, the larger acoustic signal measured with the airfoil installed and corresponding spectra of increased peak level are plotted together with those obtained for the isolated source. It is also seen from Fig. 10 that the shielding levels obtained with the source positioned, respectively, at the airfoil's leading edge and trailing edge stations only differ when the observer is located in the "deep" shielding (or shadow) region; i.e., upstream of the airfoil when the source is positioned at the trailing edge station, and downstream of the airfoil when the source is positioned at the leading edge station. Thus, an additional $2 \mathrm{~dB}$ in shielding is measured in the "deep" shadow region when the source is positioned at the leading edge of the airfoil versus the trailing edge. This could possibly be indicative of an edge geometry effect (smooth and round leading edge versus sharp trailing edge) on the scattering of the sound. One possibility is that the sharp trailing edge could be more effective at scattering sound at large angles, into the "deep" shadow region, as compared to the smooth and round leading edge. However, as the directive behavior of each edge's scattering was not isolated in this experiment, no conclusion can truly be drawn at those particular observer locations.

Finally, as also shown in Fig. 10, positioning the source further towards the mid-chord station of the airfoil leads to an increase in shielding. With the source at $50 \%$ chord, slightly greater shielding levels are measured upstream of the airfoil mid-chord station (leading edge scattering) than downstream (trailing edge scattering), which is consistent with the possible "edge effect" discussed above. For the locations closer to mid-chord shown, the source is shielded by the airfoil at all of the observer locations surveyed. The localized decrease in shielding (seen as a "bump" in the shielding curves) obtained at microphone location $\mathrm{x}=-20 \mathrm{~mm}$ when the source is at $\mathrm{x}=150 \mathrm{~mm}$ (and at microphone location $\mathrm{x}=10 \mathrm{~mm}$ when the source is at $\mathrm{x}=140 \mathrm{~mm}$ ) is associated with the sound that is scattered at the trailing edge of the airfoil reaching the microphone at nearly the same time as the sound that is scattered at the leading edge, resulting in the measure of a stronger acoustic pressure signal at that location. The acoustic signals (and corresponding spectra) obtained, respectively, at observer locations, $\mathrm{x}=0,-20$ and $-100 \mathrm{~mm}$ when the source is at $\mathrm{x}=150 \mathrm{~mm}$ are shown in Fig. 12. It is seen that the presence of two separate pressure pulses (one from the sound scattered at the airfoil leading edge and the other from the sound scattered at the trailing edge) in the time signal results in a significant interference pattern in the corresponding spectra, and that this interference pattern is accentuated when the two pulses are closer in amplitude. This illustrates the importance of the relative phase (timing) and amplitude of the two pulses on the resulting spectra and consequently on shielding levels.

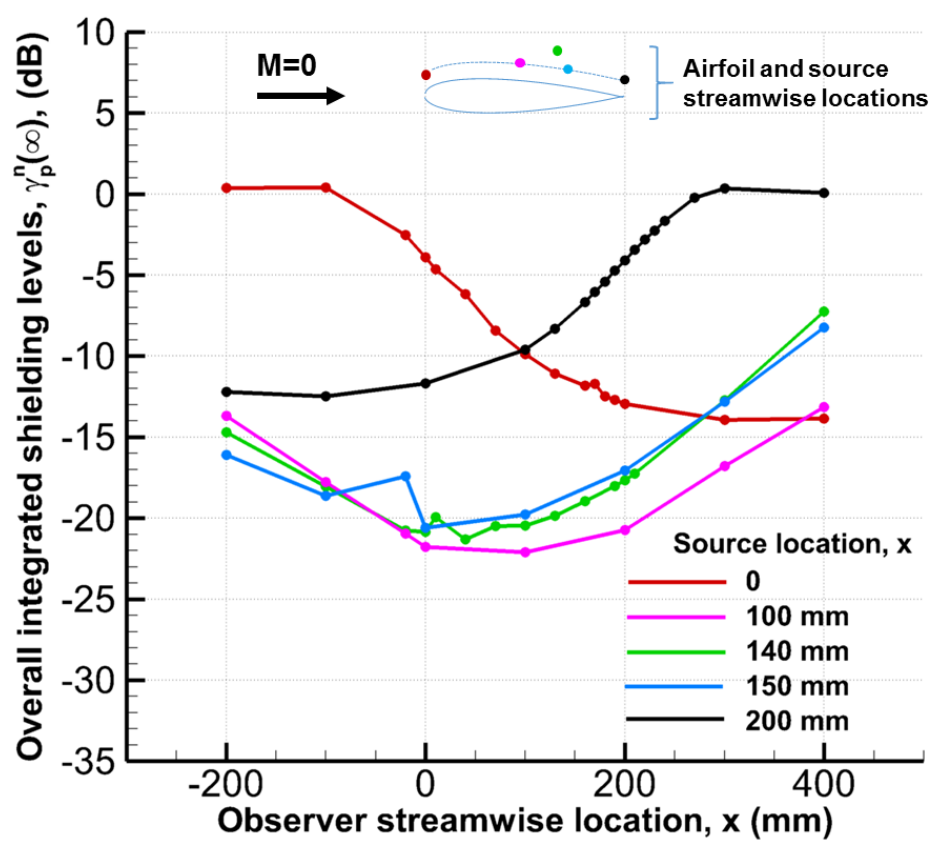

Figure 10. Effect of source location on overall shielding levels; observer line located 1 chord away from the test section centerline; airfoil $\mathrm{AOA}=0^{\circ}$; Mach $=0$; markers on curves correspond to measurement locations. 


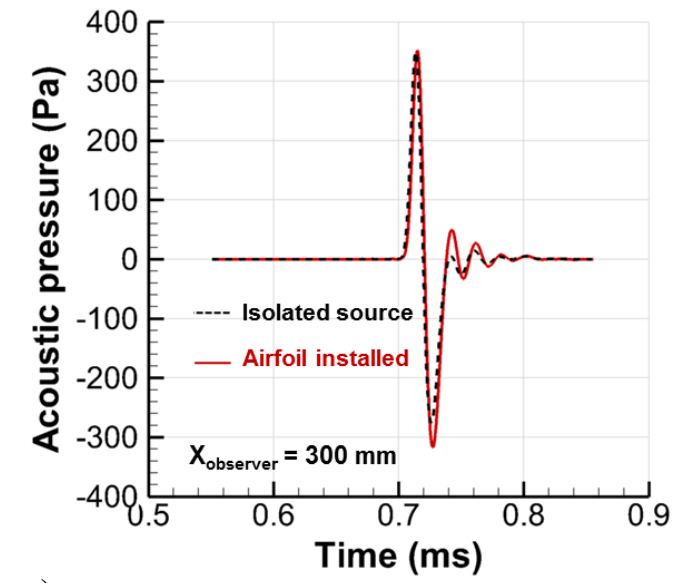

a)

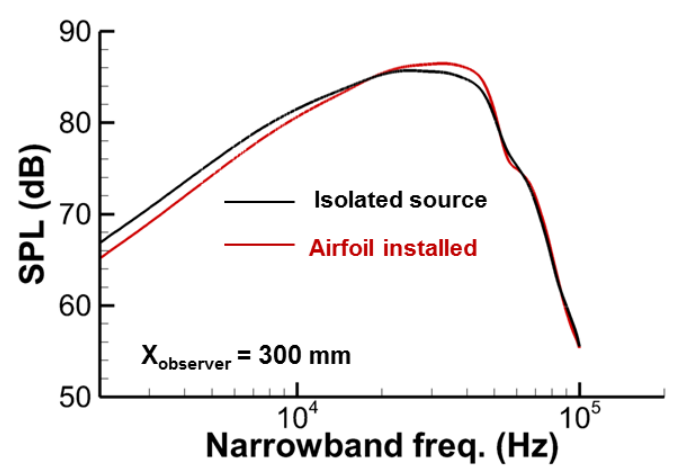

b)

Figure 11. a) Acoustic time signals; b) Spectra; Source at $x=200 \mathrm{~mm}$ (airfoil trailing edge station), observer at $x=300 \mathrm{~mm}$ and 1 chord away from the test section centerline; airfoil $\mathrm{AOA}=0^{\circ}$; $\mathrm{Mach}=0$.
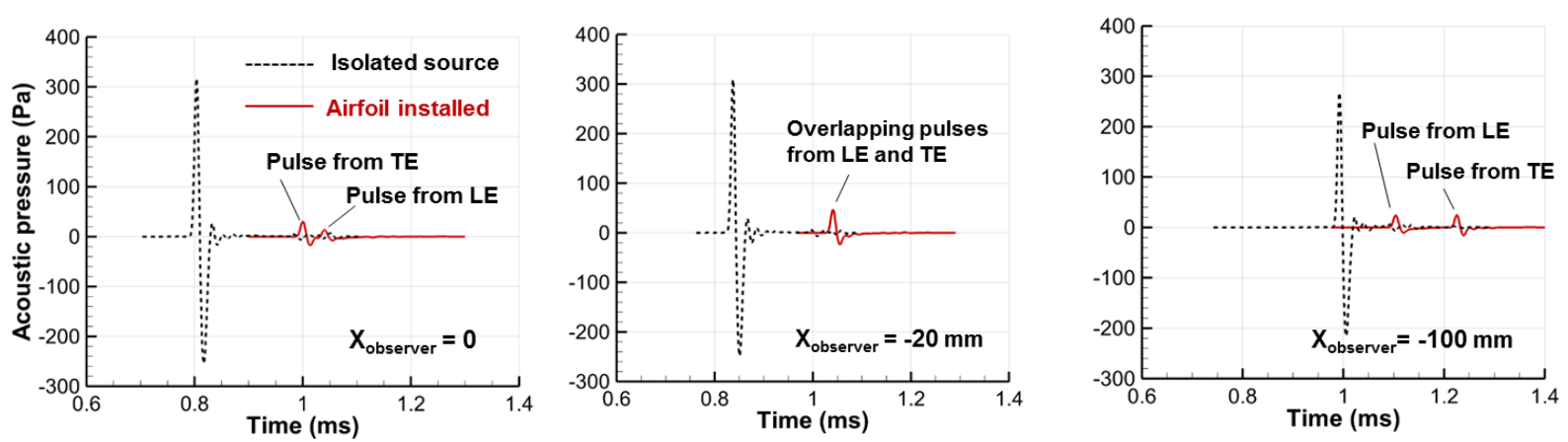

a)
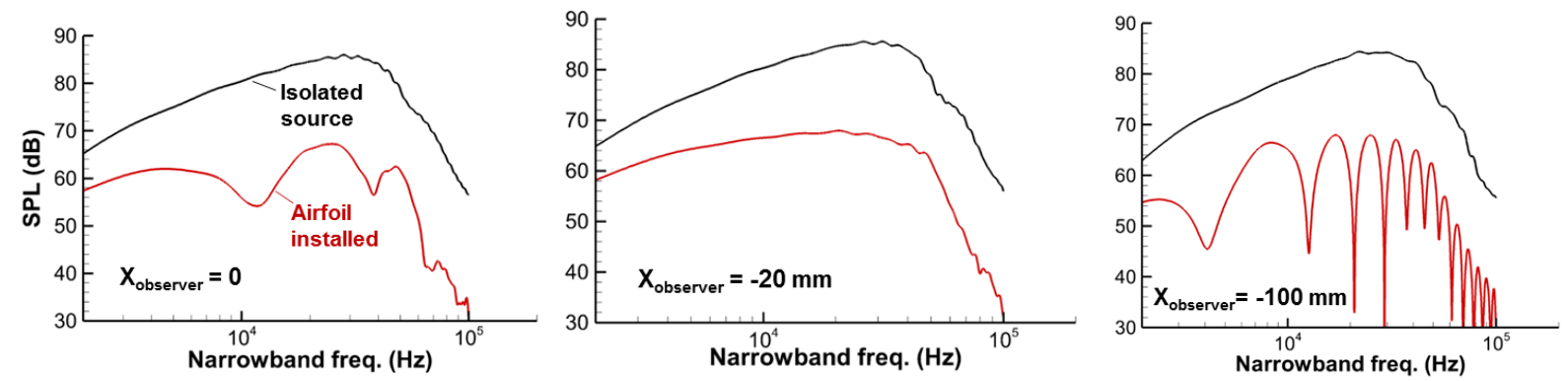

b)

Figure 12. Source at $x=150 \mathrm{~mm}$; observer 1 chord away from test section centerline and streamwise location is as indicated; airfoil $\mathrm{AOA}=0^{\circ}$; $\mathrm{Mach}=0 ; \mathrm{LE}$ : airfoil leading edge; TE: airfoil trailing edge; a) Acoustic time signals; b) Spectra. 


\section{B. Effect of flow}

The shielding levels obtained with and without freestream flow for the same source and observer locations discussed above are presented in Figs. 13, 14 and 15. The airfoil angle of attack is $0^{\circ}$. When the source is positioned at the airfoil leading edge station (Fig. 13a), the overall shielding levels, $\gamma_{p}^{n}(\infty)$, slightly increase with increasing Mach number, while shielding levels significantly decrease with flow for the other source locations (Figs. 14a and 15a). Potential contributors to these changes in shielding levels with flow might be: (1) drift in source location; (2) change in source directivity; and (3) refraction from the flow velocity gradient present near the airfoil surface. Although, it was noted earlier that during sound emission, the source convects with the flow (estimated to be a $6 \mathrm{~mm}$ total transit distance when the flow Mach number is 0.16), it is believed to be unlikely (although unknown) that such a small drift in source location could noticeably affect the measured shielding levels. It would certainly not solely explain the decrease in shielding (by up to $3 \mathrm{~dB}$ when the flow Mach number is 0.16 instead of 0 ) that is obtained when the source is positioned well inboard of the airfoil (Fig. 15a) and remains fully shielded at all observer locations.

A change in the source directivity might be expected to have more of an impact (although the amount is again unknown) on the noise levels that are measured at each observer location. Thus, the relative amplitude of the acoustic signals (pressure pulses) received at a given microphone location and corresponding to the sound that is scattered at the leading and trailing edges of the airfoil would change with source directivity. This, in turn, would be expected to affect spectral shape and possibly shielding levels. The changes in shielding levels and in source directivity were also noted to occur in the same frequency bands. Thus, a comparison of the shielding levels obtained with and without flow over each octave band is shown in Figs. 13b, 14b and 15b for, respectively, three different source locations. These figures indicate that the presence of the flow significantly affects shielding levels in the two highest frequency bands $\left(\mathrm{f}_{\mathrm{c}}=28 \mathrm{kHz}\right.$ and $56 \mathrm{kHz}$ ) while the levels in the two lower frequency bands remain nearly unchanged.

The more likely reason for the changes in shielding observed with flow might be sound refraction from the flow velocity gradient present near the airfoil surface. For this effect, the sound that is scattered at the leading edge of the airfoil and traveling downstream would tend to be refracted towards the airfoil by the mean velocity gradient of the boundary layer, away from the observers (increased shielding), while the sound that is scattered at the trailing edge and traveling upstream would tend to be refracted away from the airfoil by the boundary layer, towards the observers (decreased shielding). This is consistent with and could explain the slight increase in shielding that occurs with flow when the source is positioned at the airfoil leading edge station and the decrease in shielding observed when the source is at the trailing edge station.

For all of the $0^{\circ}$ angle of attack test cases discussed above, the rms and averaged-signal spectra remained nearly identical to each other for each of the flow Mach numbers tested, indicating the absence of signal scatter while travelling through the airfoil wake to the microphone. Thus, it is not believed that the calculation of the shielding levels in the presence of flow were affected by airfoil wake turbulence. The effect of acoustic signal scatter on the measured shielding levels is further discussed at the end of Section 5c.

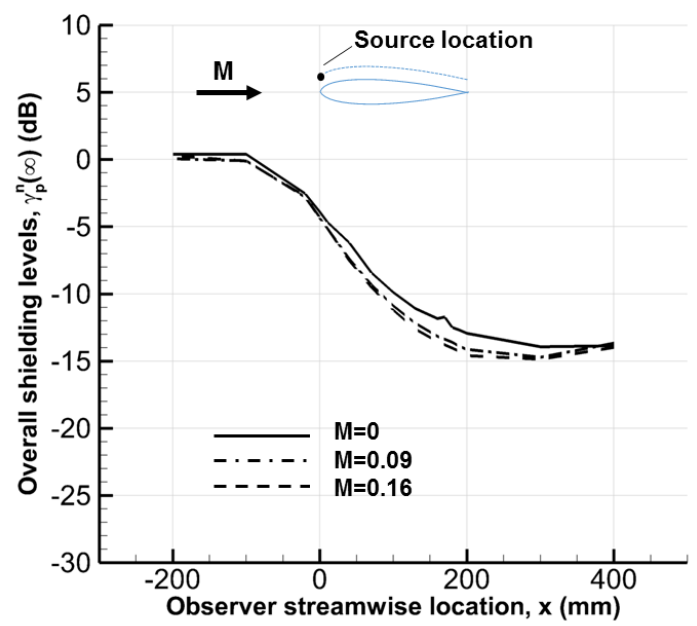

a)

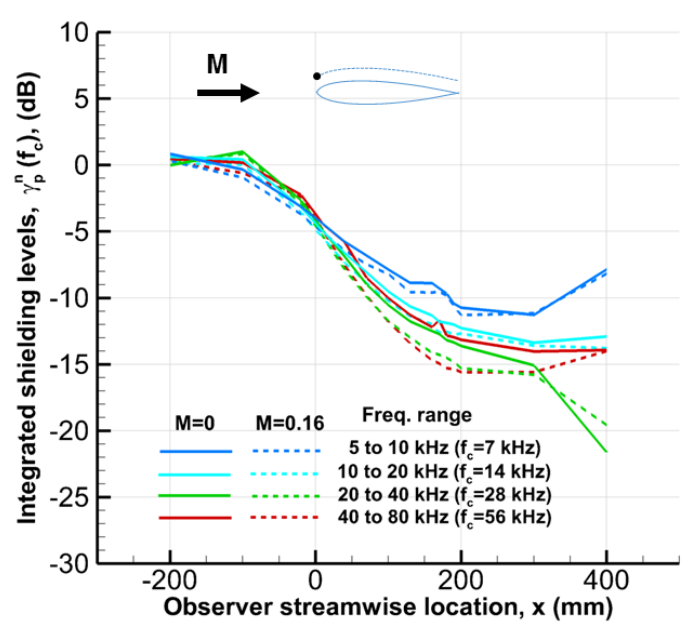

b)

Figure 13. Effect of flow on shielding levels; Source at $x=0 \mathrm{~mm}$; observer line located 1 chord $(20 \mathrm{~cm})$ away from the test section centerline; airfoil $\mathrm{AOA}=0^{\circ}$; a) Overall shielding levels; b) Octave band shielding levels. 


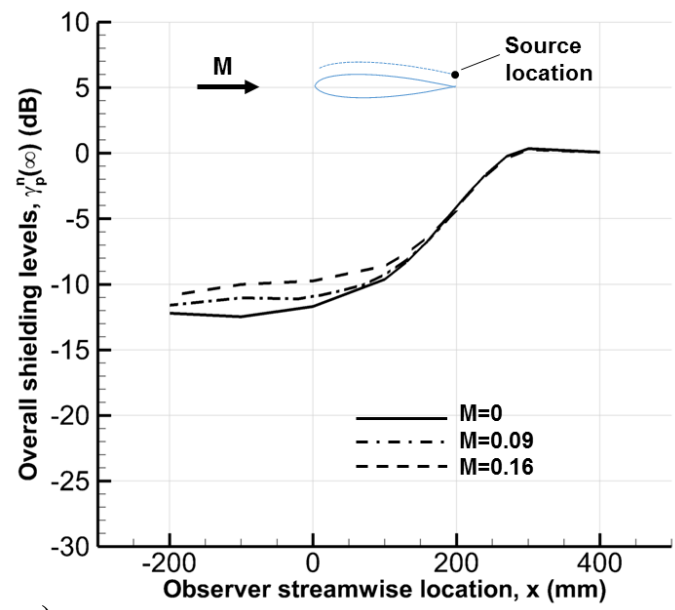

a)

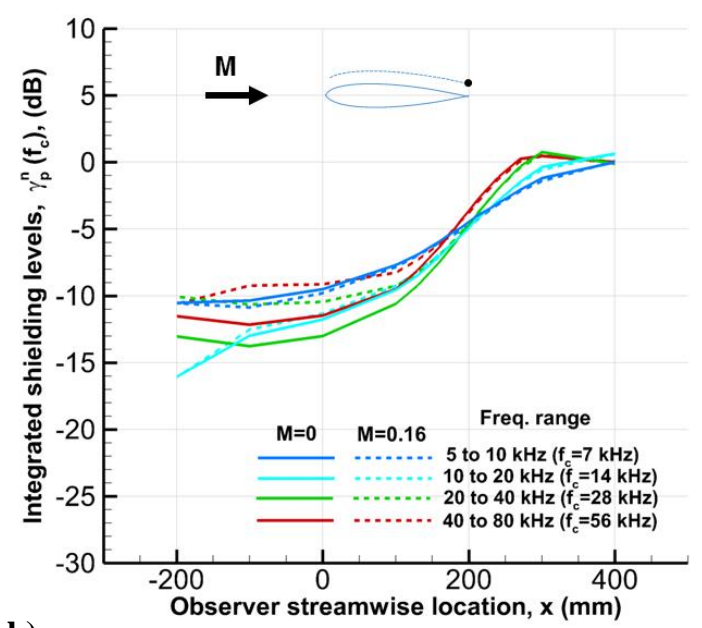

b)

Figure 14. Effect of flow on shielding levels; Source at $x=200 \mathrm{~mm}$; observer line located 1 chord away from the test section centerline; airfoil $\mathrm{AOA}=0^{\circ}$; a) Overall shielding levels; b) Octave band shielding levels.

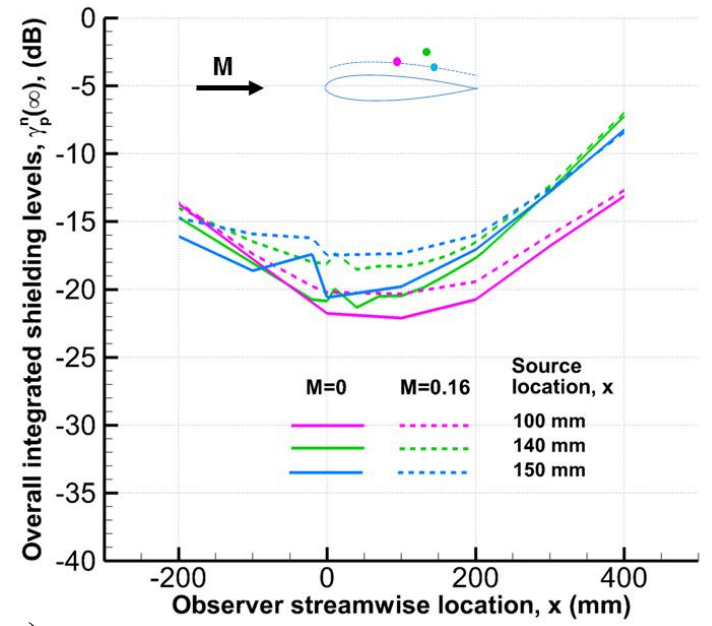

a)

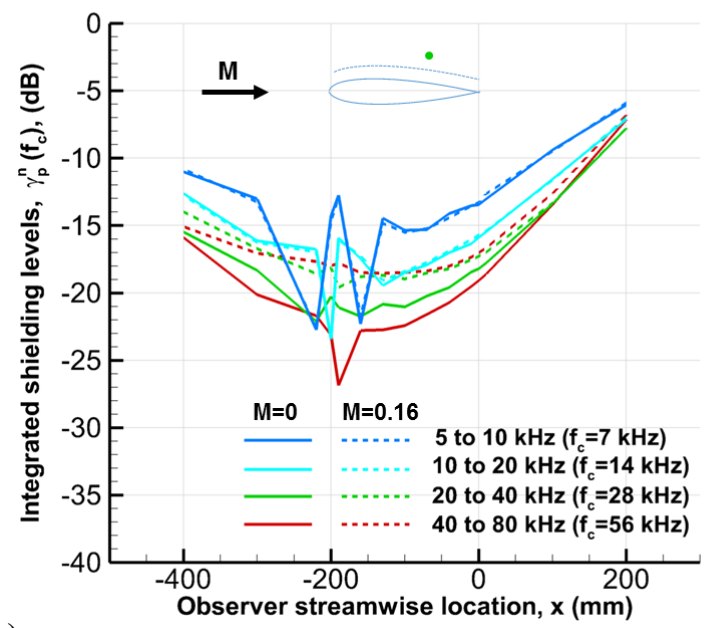

b)

Figure 15. Effect of flow on shielding levels; source location as indicated; observer line located 1 chord away from the test section centerline; airfoil $\mathrm{AOA}=0^{\circ}$; a) overall shielding levels for 3 source locations; b) Octave band shielding levels for source at $x=140 \mathrm{~mm}$ (and $40 \mathrm{~mm}$ from airfoil surface).

\section{Effect of angle of attack}

The overall shielding levels obtained for the three angles of attack tested $\left(0^{\circ}\right.$ and $\left.\pm 13.1^{\circ}\right)$ are compared in Fig. 16, Fig. 17a and Fig. 17b for three different source locations. In each of these figures, the observer line is one chord away from the test section center line.

It is shown in Fig. 16, that when the source is positioned at the trailing edge of the airfoil, for the no-flow cases, a change in angle of attack from $0^{\circ}$ to $13.1^{\circ}$ leads to a shift of the shielding level curve upstream while a change to a negative angle of attack $\left(-13.1^{\circ}\right)$ leads to a shift in the downstream direction. These shifts appear to be a direct result of the changes in shielded and unshielded observer locations associated with each airfoil setting. For the $-13.1^{\circ}$ angle of attack case, lower levels of shielding occur at the most upstream observer locations than with the other two angle 
of attack settings, as the path of the sound radiating upstream is not as well blocked by the airfoil; while for the $13.1^{\circ}$ angle of attack case, a slightly larger increase in noise is measured at the most downstream locations when the airfoil is installed, as the observers receive more "direct" reflections from the airfoil surface than with the other two angle of attack settings.

With flow on, a similar decrease in shielding is observed in Fig. 16 for the $0^{\circ}$ and $13.1^{\circ}$ angle of attack cases. However, for the $-13.1^{\circ}$ angle of attack configuration, the initial decrease in shielding that is observed as the microphone moves upstream is followed by a significant increase in shielding for the two most upstream observers. Examination of the time signals recorded at these locations revealed an overlap between the pressure pulses received, respectively, from the leading edge and trailing edge of the airfoil; a signal overlap that results in a "combined" pressure pulse of reduced amplitude (destructive signal interference) and thus, increased shielding levels.

When the source is positioned at the airfoil leading edge station (Fig. 17a), the shielding curves for the no-flow cases are observed to shift (upstream or downstream) with angle of attack change as when the source was positioned at the airfoil trailing edge station. It is also shown in Fig. 17a, that unlike for the $0^{\circ}$ and $13.1^{\circ}$ angle of attack cases, the presence of the flow leads to a slight increase in noise when the airfoil is at $-13.1^{\circ}$ angle of attack. This increase in noise is believed to be associated with stronger leading edge reflections resulting from the downstream amplification of the sound source. At $13.1^{\circ}$ angle of attack, however, the increased shielding levels induced by the presence of the freestream flow are only observed upstream of the airfoil trailing edge station. The significant decrease in shielding measured downstream of the trailing edge appears to be again related to the signals produced by the sound that is scattered at the leading edge and trailing edge of the airfoil reaching these downstream locations at nearly the same time. Examination of the time signals again revealed two pressure pulses that overlap and (in this case) "combine" into a pressure pulse of increased amplitude (constructive signal interference).

Finally, with the source at $70 \%$ chord (Fig. 17b), the angle of attack change leads to a "tilt" of the shielding curves (counter-clockwise for a positive angle of attack change and clockwise for a negative one), while the presence of the flow induces a significant decrease in shielding (of up to $3.5 \mathrm{~dB}$ ) in the shadow regions regardless of the angle of attack setting.

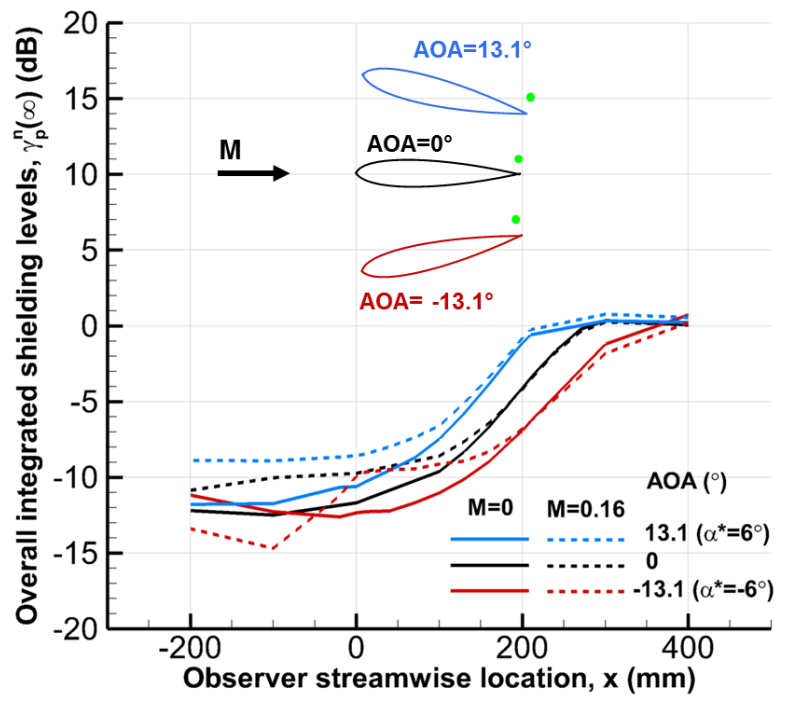

Figure 16. Effect of angle of attack (AOA) on overall shielding levels; source located at airfoil trailing edge; observer line located 1 chord away from the test section centerline. 

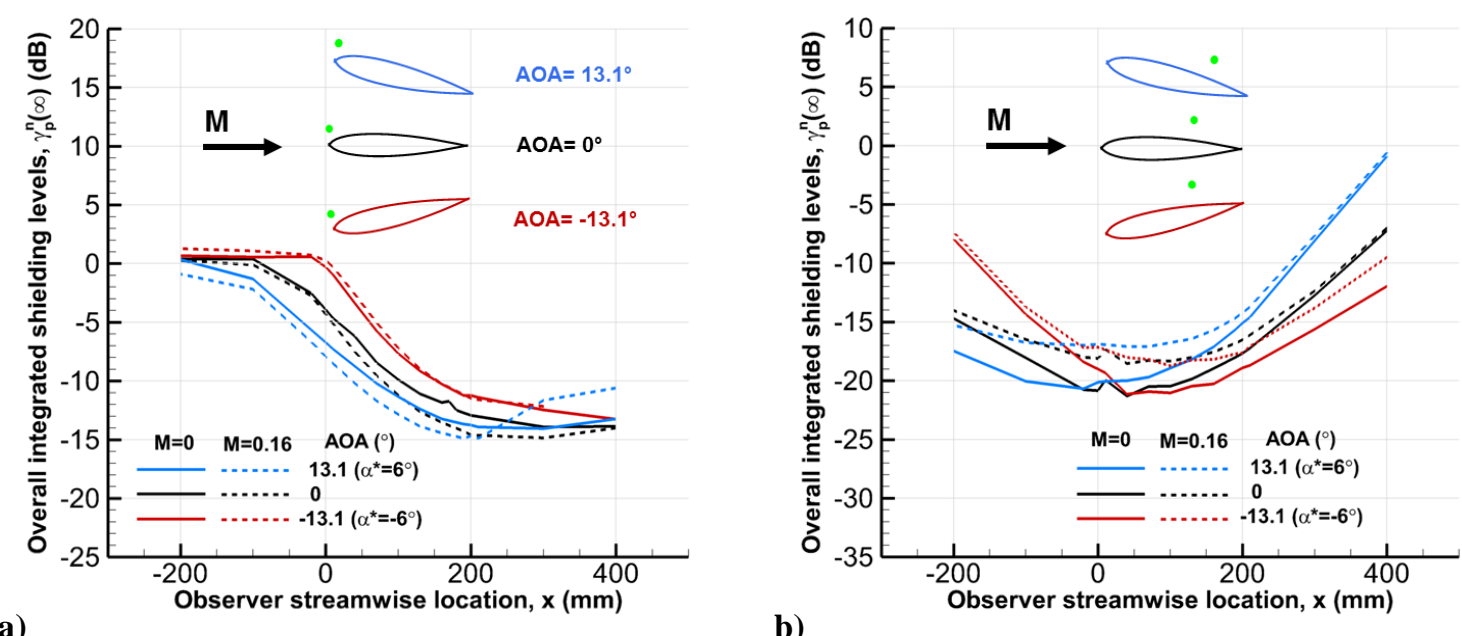

Figure 17. Effect of angle of attack (AOA) on overall shielding levels; observer line located 1 chord away from the test section centerline; a) source located at airfoil leading edge ( $25 \mathrm{~mm}$ from the airfoil surface); b) source located at $70 \%$ chord $(\mathbf{4 0} \mathrm{mm}$ from the airfoil surface).

Note that the shielding levels presented in Figs. 16, 17a and $17 \mathrm{~b}$ for the $-13.1^{\circ}$ angle of attack cases with flow were calculated from the rms spectra. While nearly identical for the other two angles of attack, the shielding levels calculated from the rms and averaged-signal spectra for the $-13.1^{\circ}$ angle of attack test cases (with flow) differed by up to $0.5 \mathrm{~dB}$. Examination of the time signals revealed that for these test cases, the acoustic pulses generated by each plasma burst (100 per data point) arrived at the survey microphones with slightly more scatter (i.e., variation in travel time). An example of signal scatter is provided in Fig.18. The individual and averaged time signals received at an observer located at $\mathrm{x}=400 \mathrm{~mm}$, with and without the airfoil installed are shown. The flow Mach number is 0.16 and the source is not shielded by the airfoil at that observer location. The increase in signal scatter observed between Fig. 18a (isolated source) and Fig. 18b (airfoil installed at $\mathrm{AOA}=-13.1^{\circ}$ ) does not appear to be associated with airfoil wake turbulence, as such scatter was not observed with the other angle of attack settings. The scatter (which leads to a reduced averaged time signal, which in turns results in "artificially" increased shielding levels) appears to be, instead, associated with increased turbulence from the test section shear layer which is pulled closer to the survey line with this airfoil angle of attack setting. A more comprehensive discussion of the facility shear layer turbulence on the measured pulse propagation is given in a companion paper. ${ }^{14}$ The use of rms spectra which are based on the individual time signals (instead of the averaged one) lessens the effect of this scatter on shielding levels. However, in the results displayed in Figs. 16, 17a and $17 \mathrm{~b}$ for the $-13.1^{\circ}$ angle of attack test case, additional low frequency noise contamination from shear layer gusts hitting the microphone affected the rms spectra obtained at the most downstream locations. Thus, in Fig. 17a, the overall shielding level for an observer at $x=400 \mathrm{~mm}$ could not be reliably calculated and is not shown; and the overall shielding level values plotted for observers at $x=210,300$ and $400 \mathrm{~mm}$ in Fig. 17b and for an observer at $x=400 \mathrm{~mm}$ in Fig. 16 were calculated over a reduced frequency range of 10 to $80 \mathrm{kHz}$. 


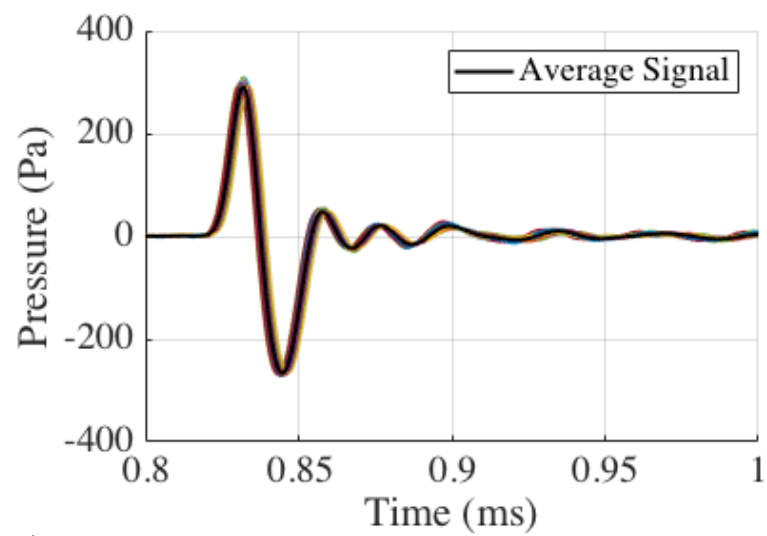

a)

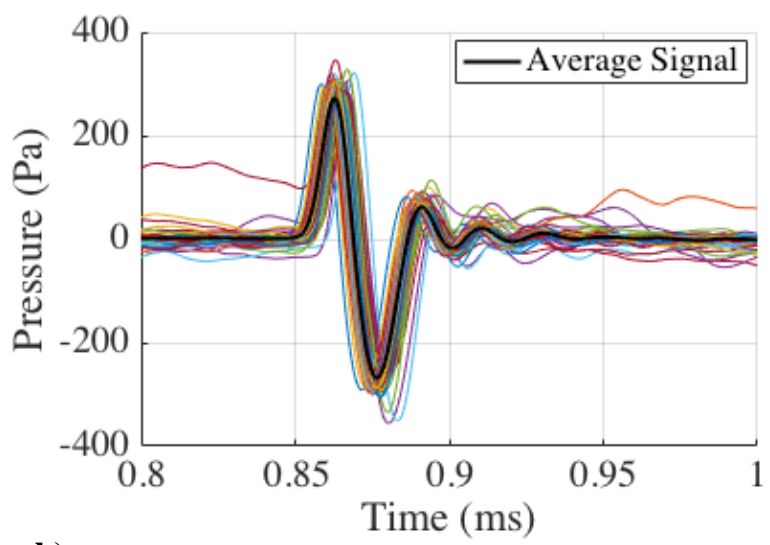

b)

Figure 18. An example of signal scatter; source at airfoil trailing edge location; the observer is unshielded and located 1 chord $(20 \mathrm{~cm})$ away from the test section centerline, at streamwise station, $x=400 \mathrm{~mm}$; airfoil AOA $=-13.1^{\circ}\left(\alpha^{*}=-6^{\circ}\right)$; Mach $=0.16$. a) isolated source; $\left.b\right)$ airfoil installed.

\section{Effect of observer distance to airfoil}

The overall shielding levels measured in the survey lines that are, respectively, 1 chord and 2 chords away from the wind tunnel centerline are compared in Fig. 19 for a subset of source locations. The airfoil is at $0^{\circ}$ angle of attack and the flow Mach number is 0 . Shielding levels measured in the two different observer lines would be expected to match only if these observers are within the same directivity angle of the sound that is scattered from both the leading edge and trailing edge of the airfoil. This will, however, not happen until the observer line is positioned sufficiently far away for these two "sound sources" to appear as a compact source. Thus, in Fig. 19, shielding levels measured in the two different survey lines only match when the observers from each line are at the same streamwise station as the airfoil trailing edge (or leading edge) and the sound scattered at that edge dominates the acoustic field measured at these two observer locations. In these instances, the observers are at the same directivity angle of the sound scattered at that particular edge (while the sound coming from the opposite edge at a different directivity angle for each observer is much weaker and doesn't significantly contribute to the shielding levels). The shielding levels measured in this experiment are therefore different from those that would be measured in the geometric far field, where the measured shielding levels would no longer change with further increase in observer distance. The airfoil to observer distance that would need to be achieved for geometric far field behavior was not determined in this experiment, but it is expected to be significantly larger than 2 airfoil chords. 


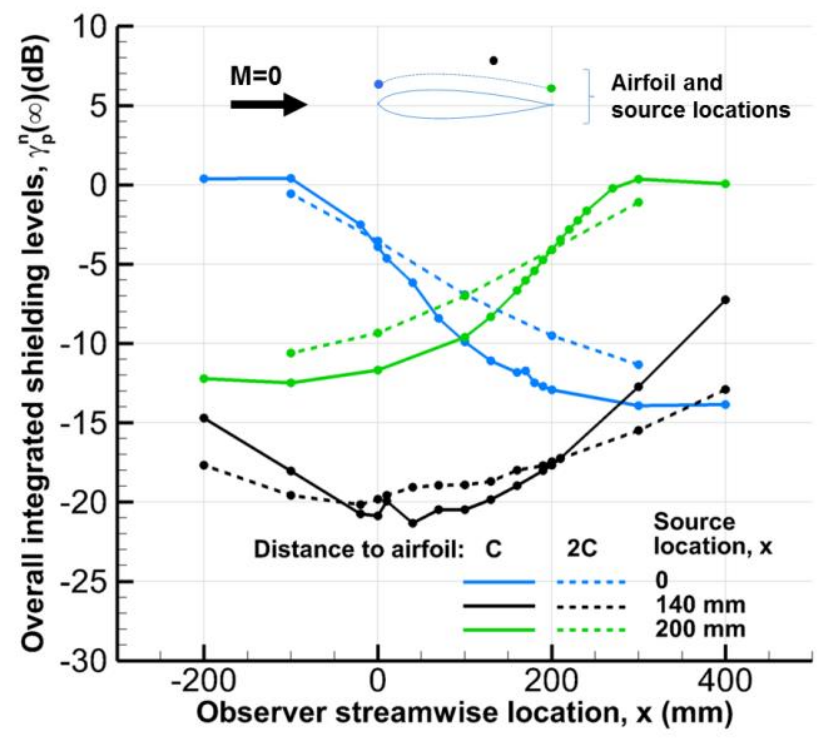

Figure 19. Effect of observer distance to airfoil on overall shielding levels; survey microphone positioned 1 chord and 2 chords away from the airfoil chordline; source at $x=140 \mathrm{~mm}$ is $40 \mathrm{~mm}$ from the airfoil surface, instead of $25 \mathrm{~mm}$ for the other 2 source locations; $\mathrm{AOA}=0^{\circ}$ and $\mathrm{Mach}=\mathbf{0}$.

\section{Summary}

A noise scattering study has been conducted at NASA Langley, DLR and ONERA to establish a common database that could be used for the development and validation of noise scattering prediction tools. The sound source was a laser-induced plasma and the scattering surface a NACA0012 airfoil. The repeatability of the acoustic signal and the expected omnidirectional character of the sound produced by the plasma burst were verified. A downstream amplification and upstream attenuation of the sound was observed in the presence of flow due to source convection during sound release. Shielding levels were shown to increase as the source is positioned closer to the airfoil midchord. Sources located at the airfoil leading edge appeared to be slightly more shielded than those at the trailing edge at opposing observer locations, possibly due to more effective scattering by the trailing edge, though this cannot be stated conclusively with the data available herein.

Except for when the source was positioned at the airfoil leading edge station, an increase in flow Mach number leads to a decrease in shielding levels. With the source at the airfoil leading edge station, the increase in Mach number leads to a slight increase in shielding. These changes observed with increasing Mach number are believed to be mostly associated with sound refraction from the mean flow velocity gradient present near the surface of the airfoil, although a drift in the source location and changes in the source directivity due to flow effects might also contribute. Both with and without flow, changes in angle of attack were associated with a corresponding shift of the shadow region. A positive angle of attack change was shown to lead to an upstream shift (with the source positioned either at the leading edge or trailing edge of the airfoil) or a counterclockwise tilt (for the mid-chord source locations) of the shielding level curves, as opposed to, respectively, a downstream shift or a clockwise tilt with a negative angle of attack change. Shielding levels measured in the present experiment were also shown to be dependent on the distance between the microphone survey line and the airfoil because of the multipath nature of the measured acoustic signal when the source is shielded by the airfoil. The multipath character of the signal also induced locations of significant decrease or increase in shielding. This resulted from constructive and destructive interference at observer positions where the signals scattered at the leading and trailing edges of the airfoil arrived at nearly the same time. Finally, signal scatter from test section shear layer turbulence and gusts were shown to affect the calculation of the shielding levels at the most downstream observer locations for the -13.1 angle of attack configuration. No signal scatter was observed from the airfoil wake. 


\section{References}

[1] Clark, L., Thomas, R., Dougherty, R., Farassat, F. and Gerhold, C., "Inlet Shape Effects on the Far-Field Sound of a Model Fan," AIAA paper 97-1589.

[2] Thomas, R.H., Burley, C.L., and Olson, E.D., "Hybrid Wing Body Aircraft System Noise Assessment With Propulsion Airframe Aeroacoustic Experiments," International Journal of Aeroacoustics, Vol 11 (3\&4), 2012.

[3] Czech, M.J., Thomas, R.H., and Elkoby, R., "Propulsion Airframe Aeroacoustic Integration Effects for a Hybrid Wing Body Aircraft Configuration," International Journal of Aeroacoustics, Vol 11 (3\&4), 2012.

[4] Hutcheson, F. V., Brooks, T. F., Burley, C. L., Bahr, C. J., Pope, D. S., "Shielding of Turbomachinery Broadband Noise from a Hybrid Wing Body Aircraft Configuration," AIAA paper 2014-2624, $20^{\text {th }}$ AIAA/CEAS Aeroacoustics Conference, Atlanta, GA, June 16-20, 2014.

[5] Doty, M. J., Brooks, T. F., Burley, C. L., Bahr, C. J., Pope, D. S., "Jet Noise Shielding Provided by a Hybrid Wing Body Aircraft," AIAA paper 2014-2625, $20^{\text {th }}$ AIAA/CEAS Aeroacoustics Conference, Atlanta, GA, June 16-20, 2014.

[6] Burley, C. L., Brooks, T. F., Hutcheson, F. V., Doty, M. J., Lopes, L. V., Nickol, C. L., Vicroy, D. D., Pope, D. S., "Noise Scaling and Community Noise Metrics for the Hybrid Wing Body Aircraft," AIAA paper 20142626, $20^{\text {th }}$ AIAA/CEAS Aeroacoustics Conference, Atlanta, GA, June 16-20, 2014.

[7] Rossignol, K-S, Pott-Pollenske, M., Delfs, J., Silbermann, J., Pereira Gomes, J., "Investigating Noise Shielding by Unconventional Aircraft Configurations," AIAA paper 2017-3195, 23 ${ }^{\text {rd }}$ AIAA/CEAS Aeroacoustics Conference, Denver, CO, 2017.

[8] Rossignol, K-S and Delfs, J., "Analysis of Noise Shielding Characteristics of a NACA0012 2D Wing," AIAA paper 2016-2795, 22 ${ }^{\text {nd }}$ AIAA/CEAS Aeroacoustics Conference, Lyon, France, 2016.

[9] Qin, Q. and Attenborough, K., "Characteristics and application of laser-generated acoustic shock waves in air," Applied Acoustics, Vol 65, pp. 325-340, 2004.

[10] Dougherty, R. P., "Advanced Time-domain Beamforming Techniques," AIAA paper 2004-2955, $10^{\text {th }}$ AIAA/CEAS Aeroacoustics Conference, Manchester, Great Britain, May 10-12, 2004.

[11] American National Standard, "Method for Calculation of the Absorption of Sound by the Atmosphere", ANSI S1.26-1995, Acoustical Society of America, Catalog No. 113-1995.

[12] Dowling, A. P. and Ffowcs Williams, J. E., "Sound and Sources of Sound," published by Ellis Horwood Limited, 1989.

[13] Rossignol, K-S and Delfs, J., "On the Relevance of Convection Effects for a Laser-generated Sound Source," AIAA paper 2015-3146, 21st AIAA/CEAS Aeroacoustics Conference, Dallas, TX, 2015.

[14] Bahr, C. J., Hutcheson, F. V., Stead, D. J., “ Assessment of Unsteady Acoustic Propagation Characteristics and Corrections in Aeroacoustic Wind Tunnels Using an Acoustic Pulse", AIAA paper 2018-XXX, AIAA Aviation Conference, Atlanta, GA, 2018. 